\title{
Physical activity on medical prescription: A qualitative study of factors influencing take-up and adherence in chronically ill patients
}

Health Education Journal 20I5, Vol. 74(6) 720-73।

(C) The Author(s) 2014

Reprints and permissions: sagepub.co.uk/journalsPermissions.nav DOI: $10.1177 / 0017896914558644$ hej.sagepub.com

@SAGE

\section{William Gasparini, Sandrine Knobé and Romaine Didierjean}

Sport and Social Sciences Laboratory, University of Strasbourg, Strasbourg, France

\begin{abstract}
Objective: This study sought to determine the effects of an innovative public health programme offering physical and sports activities on medical prescription to chronically ill patients.

Method: Semi-structured interviews were conducted with programme participants at two time points: at the start of their activity $(n=33)$ and 3 months after the first interview $(n=25)$.

Results: Findings reveal that this public health initiative engaged a very sedentary population taking starting or returning to physical exercise. Participants reported beneficial effects on their well-being and underlined the benefits of being monitoring and participating in activities with other patients.

Conclusion: For individuals interviewed, starting (or getting back to) a physical activity proved beneficial, and their evaluation of the programme shows that it matched their expectations, although study participants also expressed difficulty in shifting to physical activity independently of the programme.
\end{abstract}

\section{Keywords}

Chronic disease, France, medical prescription, physical activity, secondary prevention

\section{Corresponding author:}

Sandrine Knobé, Sport and Social Sciences Laboratory, University of Strasbourg, 14, rue René Descartes, F-67084

Strasbourg Cedex, France.

Email: knobe@unistra.fr 


\section{Introduction}

Our current way of life favours sedentary lifestyles, with increasingly more time spent sitting without physical activity. This way of life has greatly influenced the development of chronic conditions such as cardiovascular and metabolic disease (World Health Organization [WHO], 2004, 2009), although studies have shown that regular moderate intensity exercise helps to reduce several risk factors and improves many health conditions (type 2 diabetes, high blood pressure, obesity, breast or colon cancer) (Department of Health, Physical Activity, Health Improvement and Prevention, 2004; National Institute of Health and Medical Research, 2008). However, the amount of regular physical activity differs considerably both in France (Vuillemin et al., 2009) and Europe (Eurobarometer, 2010), and deep inequalities in the access to sports activities have been found to depend on factors such as the social group of origin, gender and place of residence (Gasparini and Vieille Marchiset, 2008).

A number of studies have pointed to health-related social inequalities (Basset, 2008; Graham, 2009; Mackenbach, 2005; Marmot et al., 2012; Marmot and Wilkinson, 1999; Moquet and Potvin, 2011; WHO, 2011), with susceptibility to a number of diseases being correlated with socioeconomic status. For example, the prevalence of conditions such as asthma, cardiovascular disease and obesity is higher for populations living in disadvantaged areas who engage in little or low levels of physical activity. Poverty or precariousness is known to have powerful effects on physical and mental health (Bazin et al., 2006; Chauvin and Parizot, 2005; Lebas and Chauvin, 2008). Research has shown that dietary preferences, tastes and feeding practices, and the amount of physical activity, vary according to social status, educational level and body image among other factors (Defrance, 2011). Other factors such as stress, social exclusion, unemployment and the absence of social and/or family support also have a role to play. Obesity is over-represented among blue-collar workers and people living in disadvantaged neighbourhoods or rural areas, with women being particularly at risk (Poulain, 2009).

These general observations suggest that, despite public policy promoting greater access to sports activities, there has been an overall decrease in the health-enhancing physical activity. This decrease is partly linked to social and environmental changes that have led to more sedentary lifestyles and lower fitness levels. According to WHO (2013), physical inactivity is indirectly responsible for about 2 million deaths in the world annually. In 2006, the WHO European Charter on Counteracting Obesity recommended steps to promote increased physical activity. Since the adoption of the Charter and the publication of associated recommendations by the Council of Europe, physical activity has emerged as a key priority in every European country.

Other more recent reports recommend that socially disadvantaged groups should engage more in physical activity (WHO, 2013). For these reasons, the slogan Move! has progressively become the motto incorporated into public health campaigns. In France, the National Program for Nutrition and Health, 2011-2015 encourages people to increase their physical activity and reduce inactivity at all ages (Ministry of Labour, Employment and Health, 2011a). Other national efforts include programmes to support involvement in physical and sports activities (PSA) for health enhancement such as the Obesity Programme, 2010-2013 (Ministry of Labour, Employment and Health, 2011b).

In 2011, a Policy Report published by the Haute Autorité de Santé (HAS) advocated the prescription of non-drug-based treatments for obesity, with a stress on physical activity itself (Haute Autorité de Santé, 2011). Most recently, in autumn 2012, the French Ministries for Sports and Health launched an inter-ministerial, transversal policy promoting physical activity as a major tool for improving public health.

In the context of growing awareness of the risks associated with physical inactivity, the city of Strasbourg is conducting an original experiment into the medical prescription of physical 
activity. The programme, entitled Sport/santé sur ordonnance (SSSO) or sport/health on prescription, has been developed in recognition of social and geographical inequalities in access to health care and preventive physical activity. The city's health services have begun to engage more fully with inequalities between social groups, generations and neighbourhoods in recognition of the fact that the obesity rate reaches $20 \%-25 \%$ among adults living in disadvantaged areas of the city, and is four times higher among 5- to 6-year-olds living in disadvantaged areas of the city in comparison to those living in non-disadvantaged areas of the city (Urban Community of Strasbourg, 2011).

In November 2012, people with high blood pressure, type 2 diabetes, obesity or stabilised heart disease became eligible for the receipt of physical activity prescriptions by their doctors through the SSSO programme. With a medical prescription in hand, patients were invited to contact a sports instructor working for the city of Strasbourg who would guide them towards the most appropriate PSAs. The sports instructor first carried out an in-depth interview with each patient in order to assess their fitness level, their physical capacities and their health problems. Programme participants filled in a self-assessment questionnaire about their physical condition (Ricci and Gagnon, 2009) and then performed a 6-minute walking test. Following this assessment, suggestions were made concerning participation in one or more supervised physical or sports activities (mainly gymnastics, tai chi, qigong, Nordic walking, aqua gym and rowing) and/or bike riding with an annual subscription to Strasbourg's bicycle rental service. These activities were provided free of charge to programme participants.

The objective of this study was to explore involvement in these activities through participants' accounts of their experience of the programme. More specifically, we sought to determine whether chronically ill patients who participated in the programme on medical prescription became involved in higher levels of physical activity; how, with what intensity; for which physical and social benefits; and for how long.

\section{Methodology}

\section{Approach}

This study analysed participants' self-reports elicited during semi-structured interviews held first at the beginning of the programme and then again 3 months later. The study was informed by an approach to understanding patients' perspectives as accounts influenced by both social and local factors. The method adopted aimed to provide insight into how the physical exercise offered by the SSSO programme was experienced by participants, through an analysis of their reflections and discourses about it. It was complemented by observations of some of the physical activity sessions themselves. By taking into account patients' past experiences and their present social living conditions, we aimed to explore the influence of patient careers (Goffman, 1961) and the influence of social factors on physical inactivity and engagement in sports activities.

\section{Survey methods}

A qualitative study was carried out involving a sample of patients in receipt of medical prescription for physical activity delivered by a Strasbourg doctor between January and April 2013. During this period a total of 158 patients met individually with a sports instructor responsible for guiding them towards the physical or sports activities best suited to their fitness level and condition. During the meeting, the sports instructor collected biographical data, including age, place of residence and choice of physical activity. 
Table I. Distribution of interviewees' quotas.

\begin{tabular}{|c|c|c|c|c|c|c|c|c|c|}
\hline \multicolumn{5}{|c|}{ Beneficiaries of a vél'hop subscription } & \multicolumn{5}{|c|}{ Non-beneficiaries of a vél'hop subscription ${ }^{\mathrm{a}}$} \\
\hline \multirow[t]{2}{*}{ Interviews } & \multicolumn{2}{|l|}{ Men } & \multicolumn{2}{|c|}{ Women } & \multirow[t]{2}{*}{ Interviews } & \multicolumn{2}{|l|}{ Men } & \multicolumn{2}{|c|}{ Women } \\
\hline & First & Second & First & Second & & First & Second & First & Second \\
\hline $\begin{array}{l}\text { Age } \leq \text { median age }{ }^{b} \\
\text { (53years old) }\end{array}$ & 3 & 2 & 2 & 2 & $\begin{array}{l}\text { Age } \leq \text { median age } \\
\text { (5I years old) }\end{array}$ & I & 0 & I & 0 \\
\hline $\begin{array}{l}\text { Other } \\
\text { neighbourhood }\end{array}$ & & & & & $\begin{array}{l}\text { Other } \\
\text { neighbourhood }\end{array}$ & & & & \\
\hline $\begin{array}{l}\text { Age } \leq \text { median age } \\
\text { (53 years old) }\end{array}$ & 0 & 0 & 2 & 1 & $\begin{array}{l}\text { Age } \leq \text { median age } \\
\text { (5I years old) }\end{array}$ & 2 & 2 & 4 & 4 \\
\hline $\begin{array}{l}\text { Working-class } \\
\text { neighbourhoodc }\end{array}$ & & & & & $\begin{array}{l}\text { Working-class } \\
\text { neighbourhood }\end{array}$ & & & & \\
\hline $\begin{array}{l}\text { Age }>\text { median age } \\
\text { ( } 53 \text { years old) }\end{array}$ & 3 & 3 & 2 & 2 & $\begin{array}{l}\text { Age }>\text { median age } \\
\text { (5I years old) }\end{array}$ & I & 0 & 4 & 3 \\
\hline $\begin{array}{l}\text { Other } \\
\text { neighbourhood }\end{array}$ & & & & & $\begin{array}{l}\text { Other } \\
\text { neighbourhood }\end{array}$ & & & & \\
\hline $\begin{array}{l}\text { Age }>\text { median age } \\
\text { (53 years old) }\end{array}$ & 2 & 2 & 2 & 2 & $\begin{array}{l}\text { Age }>\text { median age } \\
(5 I \text { years old })\end{array}$ & 1 & 1 & 3 & I \\
\hline $\begin{array}{l}\text { Working-class } \\
\text { neighbourhood }\end{array}$ & & & & & $\begin{array}{l}\text { Working-class } \\
\text { neighbourhood }\end{array}$ & & & & \\
\hline$n$ & 8 & 7 & 8 & 7 & $n$ & 5 & 3 & 12 & 8 \\
\hline
\end{tabular}

aGymnastics, tai chi, qigong, Nordic walking, aqua gym, swimming or rowing.

bThe median age is derived from the database of 158 patients who made up the sample.

'These were districts known as zones urbaines sensibles, or of districts regarded as poor in terms of people's incomes.

All data were entered into a database from which we then selected a sub-sample, representative of patient diversity and selected physical activities. Several criteria informed selection - including the type of physical activity chosen (i.e. a supervised activity such as swimming or Nordic walking, or a subscription to Strasbourg's bicycle rental service), age, type and place of residence - in order to obtain quota samples of potential interviewees (Table 1). A total of 33 patients were interviewed, with the majority being obese or overweight.

\section{Data collection}

Patients were interviewed at two different points in time: on entry into the SSSO programme (on the occasion of the first physical activity session) and then 3-4 months later. The first wave of interviews took place between March and May $2013(n=33)$. Each interview lasted about 1 hour and took place in the Department of Sport and Recreation at the Strasbourg city council. ${ }^{1}$ A second wave of interviews - involving the same patients - took place between June and July 2013. On this occasion, participants were asked about their physical activity experiences on the SSSO programme over at least a 3-month period. Unfortunately, some patients could not be interviewed again for medical reasons or because their address had changed, and only 25 patients participated in this second round of interviews (Table 1).

\section{Data analysis}

Interviews were conducted with the help of an interview guide (Table 2) covering several topics. However, a flexible approach to data collection was adopted in line with the commitments of a qualitative and interpretative approach (Miles and Huberman, 1994). Interviews were transcribed in full and then thematically (Blanchet and Gotman, 2007), and content was analysed (Krippendorff, 
Table 2. Thematic framework informing the interview guide.

Interview I Interview 2

Relationship to physical and sporting activities

(a) Present physical and/or sports practice

(b) Past physical and/or sports practice

Relationship with the SSSO programme

(a) Evolution through the programme

(b) Practice through the programme

(c) Opinions on the programme

Health
(a) Motivation behind involvement in the programme
(b) Evolution of health condition
(c) Impact(s) of the programme

Biographical factors
(a) Place of residence and residential mobility
(b) Education and employment
(c) Family life
(d) Leisure

Relationship to physical and sporting activities

(a) New physical and/or sports practices

Relationship with the SSSO programme

(a) Practice through the programme (continuation /cessation / new practices)

(b) Opinions on the programme

Health

(a) Evolution of health condition

(b) Impact(s) of the programme

Biographical factors

(a) Possible modifications/change

SSSO: Sport/santé sur ordonnance.

2003) to highlight similarities and differences. The main social characteristics of the interviewees are presented in Table 3.

\section{Ethical review}

This work did not require ethical review under Regional Health Agency of Alsace arrangements at the time.

\section{Results}

Strasbourg's SSSO programme provides mainly for chronically ill patients, and the majority of the participants were obese or overweight. More than half $(62.7 \%)$ of the patients were women, and the average age of the population was about 49 years. Slightly more than half $(52.9 \%)$ of the patients lived in the poorest districts of the city. This over-representation was particularly pronounced for women, with $71.6 \%$ living in poverty zones. In these neighbourhoods, access to sports facilities (stadiums, sports halls and gyms) is more limited.

\section{Participants' relationship to PSAs}

Interviewed patients felt 'distant' from physical activity and sports, both in terms of practice and knowledge. As shown by other surveys conducted among similar populations, interviewees had rarely been involved in PSAs. Many had been overweight in their youth and their parents had not encouraged sports activity in a club or with the family. Their current living conditions were characterised by limited social, cultural and financial resources, which limited participation in regular PSAs, especially in a club. Personal life events such as divorce, separation from children or frequent relocations were additional obstacles to regular PSA. For patients living in precarious 
Table 3. Main social characteristics of the interviewees at first interview.

\begin{tabular}{lc}
\hline Characteristics & Interviewees \\
\hline Age (in years) & \\
\hline Average & 51.3 \\
Range & $21-72$ \\
Gender & $n(\%)$ \\
\hline Men & $13(39.4)$ \\
Women & $20(60.6)$ \\
Family status & \\
Married/partner & $20(60.6)$ \\
Widowed & $2(6.1)$ \\
Divorced & $4(12.1)$ \\
Single & $7(21.2)$ \\
Place of residence & \\
\hline Working-class district & $16(48.5)$ \\
Other districts & $17(51.5)$ \\
\hline
\end{tabular}

situations and in disadvantaged districts, overcoming social- and health-related challenges was the main priority. Participation in physical activity was generally a secondary concern.

Finally, the illness trajectories (Corbin and Strauss, 1987, 1988; Strauss, 1992; Strauss et al., 1975) of interviewees had a strong impact on their relationship with PSAs. They often admitted to psychological difficulties and several $(n=6)$ reported seeing a psychiatrist or psychologist. Because they were overweight or obese, many reported heightened feelings of unease and discrimination (Amadieu, 2005) when tried to participate in sports in a club, because of their size and the stigma attributed to them by others (Goffman, 1963).

\section{Participants' relationship to the sport/health on prescription programme}

The analysis of the interviews clearly revealed that the SSSO programme facilitated participants' commitment to involvement in PSAs. It is important to remember that many of the patients, who had heard about the programme through the local media (daily press, municipal magazines or local television), asked their doctor to prescribe free physical activities. Some patients thus appeared to be seizing the opportunity at what for them was 'the right time'. The fact that the programme was free of charge, the constitution of 'peer' groups and the support provided to patients during physical activity sessions by professional sports instructors also played an important role. As the population under study was in great part composed of people with low or limited resources, it was highly unlikely that they would otherwise have become members of sports clubs demanding fees of over 100 euros a year:

I went there because my doctor monitors me and above all because it's free. Let's say that it was this fact that enabled me to start doing sports again; otherwise, I would have started a bit later or never... [...] It was just the right time. (Woman, 51, living in a working-class neighbourhood, practising tai chi and qigong as part of the programme, interview 1$)^{2}$

The support provided during the physical activity sessions was particularly appreciated by patients. As a first step, their doctor wrote a prescription and encouraged them to participate in the programme. Then the sports instructor guided them towards the most appropriate activities in 
accordance with their fitness level and health condition. Every patient acknowledged the significant part played by this monitoring, from the initial prescription to the actual practice of the physical activity. They also unanimously indicated that the proposed physical exercises were well suited to their health status as well as to their level of practice.

While obesity may progressively induce de-socialisation, practising an activity together with others with the same pathology can help make the stigma bearable (Goffman, 1963) and encourage first steps. People who are obese and whose weight and body size cannot be hidden from others find it far easier to exercise in the company of peers:

To be honest, when you start a new sport, you're much better off if you're with people with the same condition. At least you share the same problems and you make progress at the same pace. I like it better, rather than being in a club with only athletes who are in shape. (Man, 47 years, living in a working-class neighbourhood, practising Nordic walking and rowing as part of the programme, interview 2)

Knowing that you will be exercising with peers facilitates the start of, or the return to, an activity because the expectation is that social comparison will be easier to bear. The sociability created through physical exercise also makes it easier to share difficulties. Being together during physical exercise is a way to build motivation to combat stigma and to recover, as a group, some sort of corporal norm/normality. In addition, some obese people want to lose weight not only to resume a normal social life but also because they are considering a surgical procedure that requires weight loss beforehand.

\section{Long-term involvement and its effects}

Three months after the first interview, the majority of people claimed that they felt much better:

I feel better, I now feel good about myself. (Woman, 63 years, living in a working-class neighbourhood, practising gymnastics and swimming as part of the programme, interview 2)

Each time I exercise and leave my place, it's like a whiff of fresh air. (Woman, 67 years, practising fitness, Nordic walking and learning to ride a bike, interview 2)

In addition to this shared feeling, most of the participants claimed to have lost weight since starting the programme, with the loss sometimes exceeding $10 \mathrm{~kg}$ :

Without the Vélhop, ${ }^{3}$ it's clear I wouldn't have dropped 12 kilos! I would never have controlled my weight, I think. I must say, Vélhop is really what I needed! (Woman, 49 years, with a bike rental subscription, interview 2)

Other interviewees observed that their breathing and sleep quality had improved, and some even claimed that they took fewer medications. Several participants interviewed during the second phase of the study were also participating in a greater number of PSAs as part of the SSSO programme, than at the time of the first interview. This multifaceted involvement indicated a willingness to adapt personal schedules to incorporate these activities into their daily lives. In particular, 15 participants interviewed during the second phase of the investigation declared that they had changed their regular means of transport. They were now walking or riding their bicycles more frequently to go to work, to go shopping or to get to the SSSO programme sites. 
Table 4. The three socio-athletic profiles of the participants interviewed.

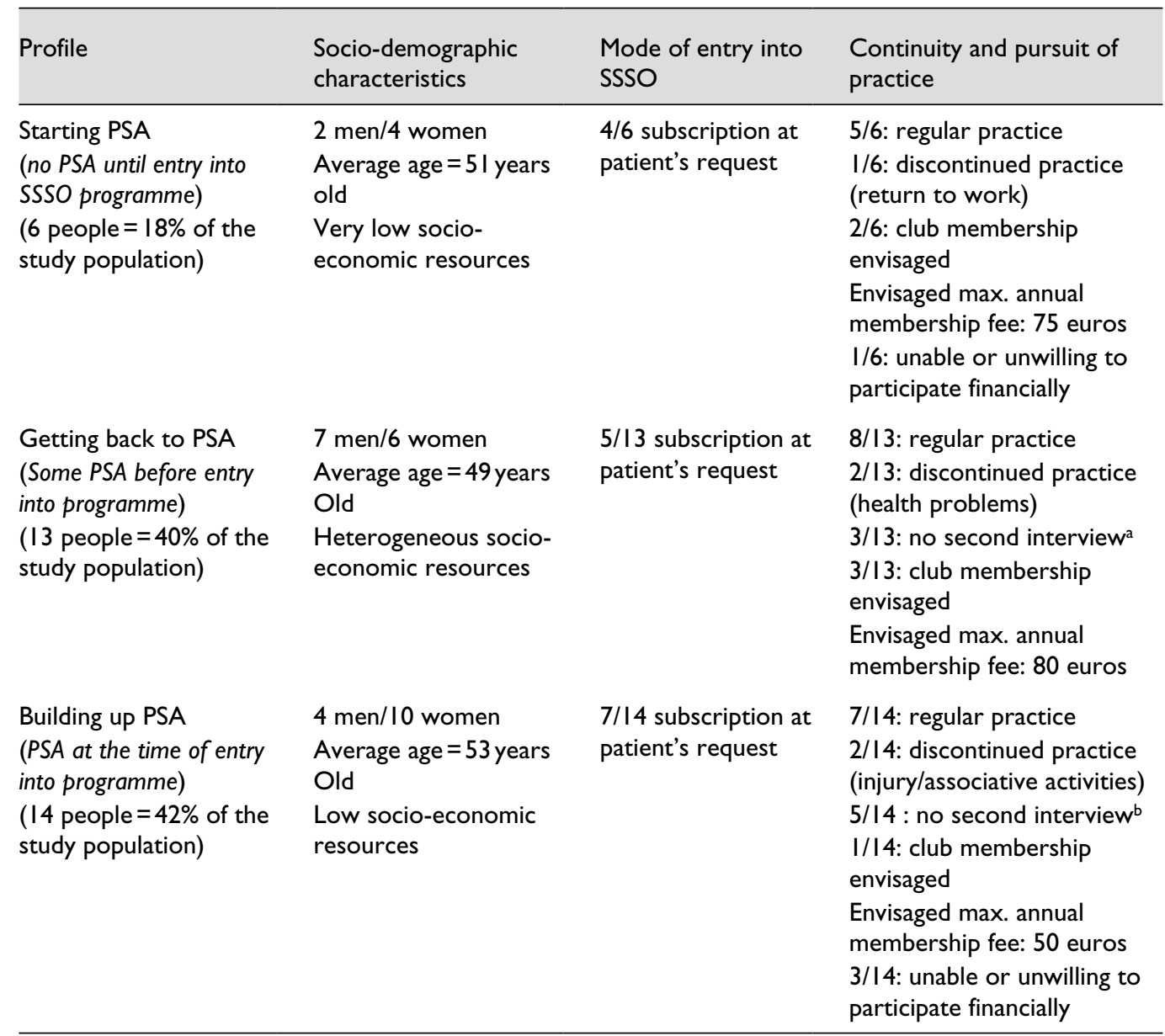

SSSO: Sport/santé sur ordonnance; PSA: physical and/or sports activity.

aThe second interview could not be conducted for the following reasons: cessation of activities inside the SSSO programme for health reasons $(n=2)$ and impossibility of contacting the interviewee $(n=1)$.

bThe second interview could not be conducted for the following reasons: absence of the interviewee at the time of the second phase of the survey $(n=I)$, cessation of activities inside the SSSO programme for health reasons $(n=I)$ or for another reason $(n=2)$ and impossibility of contacting the interviewee $(n=I)$.

It remains to be seen, however, whether these same individuals will keep practising physical activities when the programme ends. The SSSO programme is intended to help people return to, or to begin, regular PSAs in a suitable, cost-free environment, with the ultimate goal being to encourage autonomous activity. Yet, only five participants had taken the step of participating in PSAs within other structures. The vast majority admitted they preferred to remain within the support framework of the programme rather than moving on to a regular club or independent exercise. The reasons usually given were the instructors' help and high-quality supervision together with the comfort of being with peers. 


\section{The socio-athletic typology of the participants}

The results of the study suggest three profiles of patients enrolled in the SSSO programme (Table 4).

The first group could be characterised by living at a distance from the physical and/or sports culture, and thus for these patients entry into the programme meant starting PSAs, often for the first time. This profile fits 6 of the 33 participants interviewed -2 men and 4 women who had begun taking part in supervised activities primarily within the SSSO programme. More than half of them had asked their doctor to prescribe physical activities within the context of the SSSO programme. Far removed from the world of sports, these patients were also characterised by very low social and economic resources (they were essentially minimum-wage workers or employees - often retired or unemployed) and were living in subsidised housing. Most were overweight or obese, with some having associated pathologies like diabetes. All of them unambiguously acknowledged feeling the positive effects of participating physical activity, especially with regard to morale and well-being, as well as weight loss and less reliance on pharmaceutical treatment. Nevertheless, only two patients from this group considered participating in physical activities outside of the programme. Both were single, without dependent children, and with plenty of free time, and they felt able to find partners. On the other hand, all were willing to continue their activity within the programme and would even be willing to pay an annual fee, provided it was reasonable (below 80 euros).

A second group of patients could be characterised by some degree of experience in physical activity before a worsening of their pathology or a deterioration in their health status. Taking part in the SSSO programme was a way to get back to PSAs for 13 of the 33 participants interviewed. This group was made up of seven men and six women, all of whom were working and had stopped PSAs some time ago, some reporting that they had been involved in physical activities in their younger years and four reporting that they had participated in competitive sport. For this group, sports participation was an important way of building social ties. However, as for the first group, participants in this group expressed a strong desire to continue their activities within the SSSO programme - rather than in a club - and were once again prepared to contribute up to 80 euros a year on average.

The third group comprised patients who were physically active at the time of their entry into the SSSO programme, often independently walking, swimming or cycling. Five had even practised a competitive sport when they were younger. The SSSO programme was for them a way to build up PSAs. This third profile represented most of the participants interviewed - 14 out of 33. In half of the cases, individuals had asked their doctor for the medical prescription for the SSSO programme. This group was made up of minimum-wage workers or employees but they were often retired, on sick leave or unemployed. In spite of the benefits of physical activity, only one person in this group intended to continue participating in physical activity independently in a club, outside of the SSSO programme.

\section{Discussion and conclusion}

Study findings strongly suggest that the SSSO programme fulfilled its mission: encouraging patients with chronic conditions such as obesity and diabetes out of a sedentary lifestyle and into the habit of a more physically active life. The effects of the programme on health status per se were less important than its effects on quality of life, providing a stepping stone to better health. Through the medical prescription of physical activity, patients all found themselves to varying extents at a 'crossroads' in their patient career. In this sense, the programme offers patients a favourable means of gaining access to PSAs and, moreover, constitutes a drug-free treatment. For these patients, 
creating a more active lifestyle seemed to be facilitated by some of the programme features: in particular, the fact that it was free of charge and supervised by instructors with a listening ear. However, another predisposing factor was the patients' own changing representations of the health benefits of sport.

However, these results require careful interpretation because of the short timeframe of the study. Indeed, although the participants were interviewed on two occasions, the interval between the two interviews was only 3 months. One of the difficulties that must be dealt with in measures to promote involvement in PSAs is the long-term effect on the practice of target populations (Hillsdon et al., 2005); hence, the importance of longitudinal studies that follow participants over sufficiently long periods in order to better guide and orient public policies. For example, it would likely be informative to gather data on SSSO participants 1 year after the end of the programme. This type of extended investigation would provide a more accurate assessment of patient progression from initial participation to independent practice, as well as insight into obstacles to attaining autonomy. In addition, few studies of this type of public health programme have been conducted in France, which makes it difficult to compare results (Agence LH-Conseil, 2013).

Physical exercise as an alternative to medication is not so much about dealing with the health problem itself, as it is about addressing the patient's global situation in such a way that conditions are created for a change in direction out of chronic disease. The examples presented here show that patients' trajectories can evolve thanks to physical exercise. Even though the direct impact of this on the health condition is difficult to assess over such a short timeframe, many of the SSSO participants admitted feeling better, changing some of their habits, breaking out of their isolation and meeting receptive people. Participants also appreciated the chance to talk with others with the same or similar condition, and not being the only overweight or obese person in the group. They felt considerably less stigmatised in this context. However, some also expressed the desire to exercise with people not enrolled in the programme. Mixed groups of both patients and other practitioners should therefore be considered as a second step.

Doing away with medication lies at the heart of the sport/health on prescription programme: turning sport into a medicine actually involves replacing drugs with physical exercise. The effects of long-term involvement in PSAs conducive to good health have yet to be assessed in people with chronic disease. In a new socio-medical context in which patients are encouraged to manage their conditions and remain independent, physical exercise can, however, contribute to changing the way they relate to their own bodies. It is therefore appropriate to explore more fully this approach, which could be described as a form of 'self-care' (Andrieu, 2012) from a broader social perspective: asking how can physical education contribute beneficially to the career trajectory of a patient with chronic disease - to effect a lasting change in behaviour and self-transformation?

The study found that many of the programme participants lived in Strasbourg's working-class neighbourhoods, far away from areas set aside for PSAs. To improve programme attendance, it was essential to offer physical activities in the immediate vicinity of the participants' homes. As observed in other studies of access to sports activities, the geographical distance between the place of practice and the place of residence with no easy access to public transport constitutes an obstacle to regular exercise (Gasparini and Vieille Marchiset, 2008). It may also be important to improve the attractiveness of public areas that facilitate physical exercise: through staircases in apartment blocks with indications of time and caloric cost at every floor, by urban networks set aside for pedestrians and cyclists, equipped with benches and natural parkland, through designated city walks and so on.

\section{Funding}

This work was supported by the Regional Health Agency of Alsace (France). 


\section{Notes}

1. City councils of larger cities in France often have a specific department dedicated to the organisation of sports and leisure for the public.

2. All patient/personal identifiers have been removed or disguised so the individuals described cannot be identified through the details of their accounts.

3. Vélhop is a bike sharing service developed by the Urban Community of Strasbourg which enables people to hire easily a bike in the city at vélhop boutiques or automatic stations. The service offers short- or long-term, occasional or regular rental.

\section{References}

Agence LH-Conseil (2013, July) Physical activity and people with chronic disease. External evaluation: The conditions for success to build a model; dimensions portability projects. Report to the Ministry of Sports, Ministry of Health and Inpes, LH Conseil, Lille.

Amadieu J-F (2005) The obese: 'the incredible discriminated'. Available at: http://www.observatoiredesdiscriminations.fr (accessed 21 September 2014).

Andrieu B (2012) The Self-Health. Towards a Reflexive Medicine. Paris: Armand Colin/Recherches.

Basset B (2008) Regional Health Agencies. Social Inequalities in Health. Paris: INPES.

Bazin F, Parizot I and Chauvin P (2006) Psychosocial determinants of seeking care for financial reasons in five underprivileged urban areas in the Paris region. Sciences sociales et santé 24(3): 11-32.

Blanchet A and Gotman A (2007) The Interview. 2nd ed. Paris: Armand Colin.

Chauvin P and Parizot I (2005) Health and Use of Health Care for Vulnerable Populations. Paris: INSERM.

Corbin J and Strauss A (1987) Accompaniments of chronic illness: Changes in body, self biography and biographical time. Social Health Care 6: 249-281.

Corbin J and Strauss A (1988) Unending Work and Care: Managing Chronic Illness at Home. San Francisco, CA: Jossey-Bass.

Defrance J (2011) Sociology of Sport. 6th ed. Paris: La Découverte.

Department of Health, Physical Activity, Health Improvement and Prevention (2004) At least five a week. Evidence on the impact of physical activity and its relationship to health. A Report from the Chief Medical Officer, Department of Health, London, April.

Eurobarometer (2010) Sport and Physical Activity (Report). Brussels: European Commission. Available at: http://ec.europa.eu/public_opinion/archives/ebs/ebs_334_en.pdf (accessed 21 September 2014).

Gasparini W and Vieille Marchiset G (2008) Sport in Neighborhoods. Social Practices and Public Policies. Paris: PUF.

Goffman E (1961) Asylums: Essays on the Social Situation of Mental Patients and Other Inmates. New York: Doubleday.

Goffman E (1963) Stigma: Notes on the Management of Spoiled Identity. Englewood Cliffs, NJ: PrenticeHall.

Graham H (2009) Unequal Lives: Health and Socioeconomic Inequalities. Maidenhead: Open University Press.

Haute Autorité de Santé (2011) Development of non-prescription drug treatments validated. Report Guidance. Available at: http://www.has-sante.fr/portail/upload/docs/application/pdf/2011-06/developpement_de_ la_prescription_de_therapeutiques_non_medicamenteuses_rapport.pdf (accessed 21 September 2014).

Hillsdon M, Foster C and Thorogood M (2005) Interventions for promoting physical activity. Cochrane Database of Systematic Reviews 1: 1-90.

Krippendorff K (2003) Content Analysis: An Introduction to Its Methodology. 2nd ed. Thousand Oaks, CA: SAGE.

Lebas J and Chauvin P (2008) Insecurity and Health. Paris: Flammarion.

Mackenbach J (2005) Health Inequalities: Europe in Profile. Rotterdam: Erasmus MC University Medical Centre.

Marmot M, Allen J, Bell R, et al. (2012) WHO European review of social determinants of health and the health divide. The Lancet 380: 1011-1029. 
Marmot M and Wilkinson RG (1999) Social Determinants of Health. Oxford: Oxford University Press.

Miles MB and Huberman AM (1994) Qualitative Data Analysis: An Expanded Sourcebook. 2nd ed. Newbury Park, CA: SAGE.

Ministry of Labour, Employment and Health (2011a) Health programme national nutrition 2011-2015. Presentation document. Available at: http://www.sante.gouv.fr/IMG/pdf/PNNS_2011-2015.pdf (accessed 21 September 2014).

Ministry of Labour, Employment and Health (2011b) Obesity plan 2010-2013. Presentation document. Available at: http://www.sante.gouv.fr/IMG/pdf/Plan_Obesite___interactif.pdf (accessed 21 September 2014).

Moquet M-J and Potvin L (2011) Social inequalities in health: Knowledge and methods of intervention. La santé de l'homme 414: 7-43.

National Institute of Health and Medical Research (2008) Physical Activity. Contexts and Health Effects. Paris: Inserm.

Poulain J-P (2009) Sociology of Obesity. Paris: PUF.

Ricci J and Gagnon L (2009) Assessment of physical activity level and physical fitness. Available at: http:// www.best-toulouse.fr/uploaded/questionnaire-ricci-et-gagnon.pdf (accessed 9 November 2014).

Strauss A (1992) The Web of Negotiation: Qualitative Sociology and Interactionism (ed I Baszanger). Paris: L'Harmattan.

Strauss A, Corbin J, Fagerhaugh S, et al. (1975) Chronic Illness and the Quality of Life. St. Louis, MO: C.V. Mosby Co.

Urban Community of Strasbourg (2011) For health policy in the Urban Community. Document diagnostic and Community guidelines. Report, Urban Community, Strasbourg. Available at: http://www.strasbourg. eu/vie-quotidienne/solidarites-sante/sante/enjeux-sante-publique/plan-sante-cus

Vuillemin A, Escalon H and Bossard C (2009) Physical activity and sedentary. In: Escalon H, Bossard C and Beck F (eds) Nutrition Health Barometer 2008. Saint-Denis: Baromètres santé, pp. 238-268.

World Health Organization (WHO) (2004) Global Strategy on Diet, Physical Activity and Health (Report). Geneva: WHO. Available at: http://www.who.int/dietphysicalactivity/strategy/eb11344/strategy_english_web.pdf (accessed 21 September 2014).

World Health Organization (WHO) (2009) Global Health Risks: Mortality and Burden of Disease Attributable to Selected Major Risks. Geneva: WHO. Available at: http://www.who.int/healthinfo/global_burden disease/GlobalHealthRisks_report_full.pdf (accessed 21 September 2014).

World Health Organization (WHO) (2011) Rio political declaration on social determinants of health. In: World conference on social determinants of health. Geneva: WHO. Available at: http://www.who.int/ sdhconference/declaration/Rio_political_declaration.pdf (accessed 21 September 2014).

World Health Organization (WHO) (2013) Physical Activity Promotion in Socially Disadvantaged Groups: Principles for Action. Copenhagen: WHO Regional Office for Europe. 